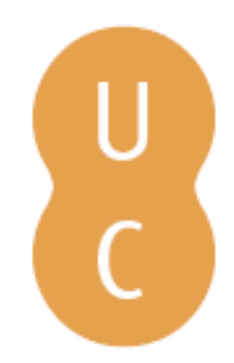

\title{
pommalina
}

\section{O Ágon cômico de Plutarco e o retórico de Aves de Aristófanes}

Autor(es): $\quad$ Teles Júnior, Paulo César de Brito; Pompeu, Ana Maria César

Publicado por: Imprensa da Universidade de Coimbra

URL

persistente:

URI:http://hdl.handle.net/10316.2/38233

DOI:

DOI:http://dx.doi.org/10.14195/978-989-26-1053-5_14

Accessed : $\quad$ 26-Apr-2023 15:28:40

A navegação consulta e descarregamento dos títulos inseridos nas Bibliotecas Digitais UC Digitalis, UC Pombalina e UC Impactum, pressupõem a aceitação plena e sem reservas dos Termos e Condições de Uso destas Bibliotecas Digitais, disponíveis em https://digitalis.uc.pt/pt-pt/termos.

Conforme exposto nos referidos Termos e Condições de Uso, o descarregamento de títulos de acesso restrito requer uma licença válida de autorização devendo o utilizador aceder ao(s) documento(s) a partir de um endereço de IP da instituição detentora da supramencionada licença.

Ao utilizador é apenas permitido o descarregamento para uso pessoal, pelo que o emprego do(s) título(s) descarregado(s) para outro fim, designadamente comercial, carece de autorização do respetivo autor ou editor da obra.

Na medida em que todas as obras da UC Digitalis se encontram protegidas pelo Código do Direito de Autor e Direitos Conexos e demais legislação aplicável, toda a cópia, parcial ou total, deste documento, nos casos em que é legalmente admitida, deverá conter ou fazer-se acompanhar por este aviso. 


\section{Grécia e Roma no universo de Augusto}

\section{Ana Maria César Pompeu Francisco Edi de Oliveira Sousa (Orgs.)}

IMPRENSA DA UNIVERSIDADE DE COIMBRA

ANNABLUME 


\title{
O agón Cômico de Plutarco \\ E O RETÓRICO DE $A V E S$ de Aristófanes \\ (The Comic agón of Plutarch and the Rhetorical agón of Aristophanes' Birds)
}

\author{
Paulo César de Brito Teles Júnior ${ }^{296}$ (pcbtji@hotmail.com) \\ Universidade Federal de Minas Gerais \\ Ana Maria CÉsar Pompeu 297 (amcpompeu@hotmail.com) \\ Universidade Federal do Ceará
}

\begin{abstract}
Resumo - Este trabalho tem como objetivo estudar o agón na obra Aves, do comediógrafo grego Aristófanes, comparado ao agón entre Aristófanes e Menandro nos Moralia, de Plutarco. Primeiramente, abordaremos como este recurso era característico da pólis grega, especialmente Atenas. Em seguida, verificaremos como o agón é construído nas obras aristôfanicas para, finalmente, analisarmos sua estrutura em Aves. Nesta peça, o párodo marca o começo de uma grande tarefa: a criação de uma cidade entre o céu e a terra junto aos pássaros, chamada de Nephelococcygia. A efetivação desta empreitada está sujeita ao sucesso que o herói cômico, Pisetero, terá no agón da comédia. Observamos que nesta parte de Aves há um debate entre quatro personagens: Pisetero, Evélpides, a Poupa e o Coro. O primeiro, que já em seu próprio nome encontramos referência à persuasão (Pisetero: “o companheiro persuasivo", "bom de lábia”), é dotado de uma incrível habilidade de convencimento e, através de seu discurso, consegue realizar seus planos.
\end{abstract}

Palavras-chave - comédia Grega, retórica, discurso, disputa.

Aвstract - This paper analyzes the agón in Aristophanes' Birds, by comparing it with the agón between Aristophanes and Menander in Plutarch's Moralia. At first we discuss how this resource was a characteristic element of the Greek pólis, especially at Athens. We then assess how the agón was formed in Aristophanes' comedies. In this play, the parodos mark the beginning of a great task: the creation of a large city between heaven and earth with the birds, called Nephelococcygia. The realization of this project is subject to the success of the comic hero Pisthetaerous in the comedy's agón. We note that in this part there is a discussion among four characters: Pisthetaerous, Euelpides, the Hoopoe and the Chorus. The first character who has a reference to persuasion in his own name (Pisthetaerous: "the persuasive friend") is gifted with an incredible ability to convince and realizes his plans through his speech.

KEYwords - Greek comedy, rhetoric, speech, dispute.

${ }^{296}$ Paulo Teles Júnior holds a degree in Language from the Federal University of Ceará. He is currently engaged in a Master's research on Old Greek Comedy at the Federal University of Minas Gerais. He is member of the "Grupo de Estudos Aristofânicos" (GEA), coordinated by Prof. Ana Maria César Pompeu.

${ }^{297}$ Ana Maria Pompeu is Associate Professor at the Federal University of Ceará. She holds a Doctoral degree in Classics from the University of São Paulo (2004). She undertook a postdoctoral research in Classics at the University of Coimbra, Portugal (2010). 


\section{UMA INTRODUÇÃo À QUESTÃo DA AGONÍSTICA GREGA}

A agonística corresponde a um espírito de disputa que perpassa campos como a retórica, a filosofia, a história e o teatro grego antigo. Sua influência é nitidamente perceptível na formação da cultura grega: o vocábulo agón é já encontrado em Homero ${ }^{298}$, sendo, portanto, empregado num momento em que a literatura ainda era transmitida de forma oral. Em seus poemas, encontramos a aristeia de alguns de seus heróis, apresentando grandes feitos. Ela consistia em uma narrativa que continha um tom moralizante e que animava a geração a que se dirigiam os cantos heroicos, vendo neles o espelho dos próprios ideais ${ }^{299}$. Nesse momento, o herói homérico, que reclamava a devida honra ao primar por glória e enaltecimento próprios, mantinha vivo o espírito de disputa.

Essa noção de concorrência é também uma marca do que conhecemos como civilização agonística. É por meio desse jogo de disputas entre os gregos que observamos também nas técnicas desportivas e em outras práticas que envolviam a concorrência entre os indivíduos, como no universo das artes e do trabalho, a manifestação de um instrumento cultural que exigia o esforço e a superação dos limites de cada um. $\mathrm{O}$ valor de competitividade possibilitava uma experiência proveitosa para o homem grego, que via os infortúnios e os problemas da existência como fatores instigantes para encarar riscos e não como algo exclusivamente danoso.

Podemos considerar o gosto dos atenienses pelos processos e pelos tribunais, de uma forma geral, como grande influência para o teatro grego através de um esquema discursivo de ataque e de defesa. Essa aproximação entre teatro e retórica é clara quando encontramos cenas de tragédias e de comédias que apresentam debates análogos aos processos judiciários atenienses ${ }^{300}$. O teatro, tido também como manifestação política, propiciava ao público tramas que faziam uso de recursos retóricos.

Encontramos estes recursos na obra de Aristófanes, principalmente no agón, que é uma estrutura formal da comédia e possui uma métrica fixa. Como estima Féral (2009: 21), trata-se de "uma seção de natureza dialética: debate entre dois contendores com a presença ou não de um árbitro e, às vezes, com a presença de uma terceira personagem ou mais". É também com essa seção que o poeta poderia alcançar efeitos dramáticos que influenciariam o sucesso de seu trabalho nos festivais.

\footnotetext{
${ }^{298}$ Um exemplo pode ser encontrado na Ilíada 23.685.

${ }^{299}$ Jaeger 2013: 70.

${ }^{300}$ Cf. Féral 2009.
} 


\section{O AGÓN NA COMÉDIA ARISTOFÂNICA: O CASO DE AVES}

O agón, segundo Duchemin ${ }^{301}$, consiste geralmente em duas tiradas opostas que simulam as posições ou as questões contrárias de duas personagens em disputa, podendo haver, excepcionalmente, três personagens. Essas tiradas são acompanhadas de uma decisão do conflito em respostas mais ágeis tornando-se um jogo de versos intercalados conhecido como esticomitia. Cabe ressaltar que o agón cômico apresenta-se de forma mais complexa do que o trágico, uma vez que, tratando-se de uma seção da comédia, possui estrutura e métrica específicas ${ }^{302}$.

Nas comédias de Aristófanes, o agón é uma parte importante e em cada peça é apresentado com forma e conteúdo diferentes. A sizígia epirremática - estrutura coordenada, que compõe o ágon, formada por discursos em tetrâmetros em que se alternam passagens cantadas e recitadas - pode se apresentar incompleta ou ausente ${ }^{303}$. Cada trabalho do poeta cômico possui uma proposta diferente, estando o agón sujeito a ela.

Sabemos que as peças iniciais de Aristófanes enfatizam a figura do poeta e descaracterizam o coro na primeira parte, enquanto que a segunda concentra-se no elemento coral. Nas peças seguintes, o coro se mostra importante nos anapestos e a sizígia epirremática é reduzida. Nas peças em que esta estrutura aparece incompleta, como em Assembleia de Mulheres e Pluto, o jogo retórico concentra-se nos argumentos dos debatedores.

O enfraquecimento destas formas fixas está ligado à redução das funções corais: o coro tende a não cumprir mais nenhum papel na ação. Isto não corresponde, no entanto, a uma eliminação, mas a mudanças adquiridas com a passagem da Comédia Antiga para a Comédia Nova.

É provável que o agón despertasse expectativas no público. As seções da peça - prólogo, párodo, agón, parábase, episódios e êxodo - possibilitavam que o comediógrafo tivesse uma influência importante acerca daquilo que o público esperava da comédia. Aristófanes podia, através desses elementos, estimular essas possibilidades, conduzindo ou confundindo o público no jogo teatral. As estruturas fixas da comédia, portanto, eram tidas como um artifício dramático. O agón tinha o objetivo de alcançar efeitos dramáticos que poderiam ajudar o comediógrafo a conseguir o prêmio no festival. ${ }^{304}$

$\mathrm{Na}$ comédia Aves, de Aristófanes, dois cidadãos atenienses, Pisetero e Evélpides, cansados da realidade de Atenas, em que os atenienses são viciados em participar de tribunais, procuram Tereu, homem transformado em pássaro pelos deuses, para dele saber de um lugar tranquilo onde pudessem morar. Quando o

\footnotetext{
${ }^{301}$ Apud Féral 2009: 20.

${ }^{302}$ Cf. Féral 2009: 21.

${ }^{303}$ Cf. Duarte 2000.

${ }^{304}$ Cf. Féral 2009: 26.
} 
encontram, Pisetero (nome cuja raiz faz referência à persuasão: "Companheiro que persuade", "Bom de Lábia”) convence Tereu de que os pássaros poderiam ser reis do universo. Pelas palavras de Pisetero, os pássaros acabam por fundar, entre o céu e a terra, uma cidade nomeada pelo próprio protagonista de Nephelococcygia, ou "Cuconuvolândia" na tradução de Adriane da Silva Duarte para o português. ${ }^{305}$

Nas cenas episódicas, temos uma inversão da ordem existente que estrutura uma utopia. E mesmo antes, na parábase da peça, já verificamos um princípio de inversão, que se constitui pela abolição das leis que regem a cidade aérea, pondo em cheque as normas sociais e morais tradicionais da pólis grega: "Quanto é vergonhoso aí [em Atenas] e coibido por lei, / isto tudo entre nós, aves, está ok.” (v. 755-756) ${ }^{306}$. O modelo de cidade perfeita é fracassado e enfrenta uma reação que restabelece os valores civilizatórios no espaço da cidade dos pássaros. A utopia do reino alado é ironicamente invadida pela realidade ateniense.

A peça Aves se apresenta, assim, como uma crítica a Atenas de sua época, sob um projeto abstrato e simbólico, fazendo referências a figuras e situações contemporâneas, como era de costume na comédia antiga. É uma obra encenada quando seu autor tinha cerca de trinta anos ${ }^{307}$. Embora considerada como uma das grandes produções aristofânicas, ela obteve o segundo lugar no concurso dramático do festival das Dionísias em que foi apresentada, no ano de 414 a.C., sendo melhor acolhida já pelos seus comentadores antigos ${ }^{308}$.

O coro abre o agón num tom solene que se assemelha ao da tragédia (v.451-459):

Coro: Traiçoeiro em todas as coisas

é por natureza o homem. Mas, apesar disso, fala!

Revelarias, talvez, uma qualidade que percebes em mim, ou uma força maior, posta de lado por meu espírito simplório.

Isto que vês, traz a público!

O que me proporcionares de bom, de todos será.

Antes de expor seu projeto, Pisetero ordena a um escravo que lhe traga uma coroa e água para lavar as mãos (v. 463-464), numa alusão aos oradores da assembleia. E assim não haverá propriamente uma discussão, nem um juiz, como costuma aparecer nos agónes das outras peças, mas uma apresentação do

\footnotetext{
${ }^{305}$ Cf. Duarte 2000.

${ }^{306}$ As traduções de Aves são de Adriane da Silva Duarte (Aristófanes 2000).

${ }^{307}$ Cf. Duarte 2000: 13.

${ }^{308}$ Cf. Silva 2006: 7.
} 
discurso do homem "bom de lábia", que tem seus fundamentos em exemplos que ressaltam que a realeza das aves foi tomada pelos deuses do Olimpo.

Pisetero continua seu discurso, deixando clara a tomada da supremacia das aves pelos deuses. Ele explica-lhes como poderiam ter sua soberania de volta, e então observamos o quão ardilosa é a construção da cidade dos pássaros nas nuvens, pois com ela a comunicação entre os homens e deuses seria prejudicada. Os sacrifícios oferecidos pelos homens aos deuses passariam a ser recebidos pelas aves, enquanto os deuses, de fome, iriam se curvar diante delas.

Há algumas oposições feitas tanto pelo coro quanto pela Poupa, mas Pisetero sempre encontra uma boa maneira de sobrepor sua fala a deles, que chegam até mesmo a "fertilizar" seu discurso, proporcionando-lhe mais ideias.

Não há necessidade de um árbitro, pois não há exatamente uma disputa entre dois personagens que expõem pontos de vistas distintos. Deste ágon participam Pisetero, Evélpides, o coro e a Poupa. O corifeu chega a afirmar que as aves estão preparadas a colocar em prática o projeto de Pisetero. Na parábase, é retomado o projeto do herói cômico, que enaltece as aves, relacionando suas origens aos mitos teogônicos.

Portanto, no plano da ação, já no prólogo, Pisetero esclarece qual é seu plano, e o párado oferece um prosseguimento da ação. Mas, o coro não está ciente ainda da empresa do herói, apenas o vê como um intruso no mundo das aves e não está aberto ao diálogo. Então, a Poupa se coloca entre as partes e estabelece uma trégua ao herói que, tendo a garantia de segurança, apresenta seu plano, expondo- o no agón, conseguindo reverter a situação e de inimigas as aves passam a aliadas.

\section{Aristófanes e Menandro sob o olhar agonístico de Plutarco nos Moralia}

Os Moralia, de Plutarco, são uma coleção de tratados que versam sobre assuntos variados, como ética, política, religião e filosofia. Entre o corpus destes tratados está o Compêndio da Comparação entre Aristófanes e Menandro, resumo de uma obra perdida de Plutarco ${ }^{309}$. O maior desafio de estudar esse texto consiste no problema de recepção dos trabalhos de Aristófanes, de Menandro e do próprio Plutarco. Trabalharemos, portanto, com três tempos e três costumes distintos ${ }^{310}$.

Menandro é o principal representante da Comédia Nova, que se desenvolve a partir do século IV a.C. Entre os comediógrafos desse período, encontramos também Alexis de Turi, Filemon, Dífilo e Apolodoro de Caristo. A única peça que chegou até nós foi o Discolo, de Menandro, obra conhecida também como Misantropo. Das outras obras, restam-nos alguns fragmentos, como do Escudo e d'A Jovem de Samos, que estão entre os mais significativos.

\footnotetext{
${ }^{309}$ Cf. Silva 2013.

${ }^{310}$ Cf. Silva 2013: 109.
} 
O caráter político, bastante acentuado na Comédia Antiga, perde força nas peças da Comédia Nova, que trabalham temáticas que se concentram na vida privada. Aristófanes de Bizâncio, como diretor da Biblioteca de Alexandria, chegou a considerar Menandro numa hierarquia de modelos a serem seguidos, logo após Homero. Nesse momento, Aristófanes era criticado por sua linguagem obscena e pelas frequentes menções à vida de seu tempo. Por outro lado, a leitura da obra de Menandro era obrigatória nas escolas de Roma e também no estudo da retórica, além de o comediógrafo ter suas peças encenadas em banquetes. ${ }^{311}$

À época do domínio imperial de Trajano, mais de duzentos anos após a morte do principal representante da Comédia Nova, Plutarco escreve suas obras. Para Hugo Bauzá (2002: 182), "sus Vidas constytuen un friso o galería de retratos donde la finalidade apunta a delinear la estampa de un conjunto de personajes que, por sus acciones, caráter e educación, se muestram dignos de ser emulados".

Nos Moralia, Plutarco dedica uma parte destinada a comparações entre Aristófanes e Menandro, elogiando o trabalho deste e, de certa forma, menosprezando o daquele. $\mathrm{O}$ texto, dividido em quatro capítulos curtos, busca analisar o léxico, o estilo e a receptividade da obra dos dois comediógrafos pelo público. Em um trecho, ressalta Plutarco:

A grosseria, o vulgar e o mau gosto na linguagem como há em Aristófanes de maneira nenhuma existe em Menandro. Pois, o espectador inculto e estúpido é convencido pelo que diz aquele, mas o espectador culto suportará de má vontade. Refiro-me às antíteses, às palavras de desinência semelhante e às paronímias. Pois um se utiliza de tais recursos de modo conveniente e raro, se ocupando destes com cuidado, mas o outro se utiliza frequentemente e de modo não oportuno e frio. [...]

Além do mais, na construção de seus discursos, está presente o trágico, o cômico, o pomposo, o vulgar, a obscuridade, a linguagem de uso comum, a faus-

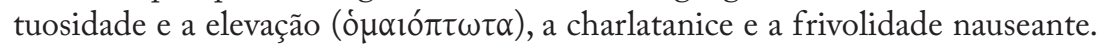
$\mathrm{E}$, com tantas diferenças e discordâncias, seu estilo não transmite o conveniente e natural a cada personagem. ${ }^{312}$

Como alerta Silva (2013), o que se mostra mais chocante no texto de Plutarco talvez seja o fato de ele não fazer nenhuma espécie de elogio a Aristófanes. Contudo, segundo a pesquisadora (2013: 114), há alguns conselhos que podem ser levados em conta:

1. O uso moderado da linguagem obscena, dos jogos de palavras, das alusões e das antíteses.

${ }^{311}$ Cf. Silva 2013: 111-112.

312 As citações do Tratado de Plutarco neste trabalho são da tradução de Luciene Lages Silva (2013). 
2. A preocupação com a unidade da personagem, de modo que os caracteres se adequem à sua natureza, disposição e idade próprias.

3. O emprego de uma linguagem ideal almejada pelo poeta e pelo orador, a qual agrade tanto ao público comum quanto ao sofisticado.

Fica-nos desse texto de Plutarco, portanto, a imagem da querela que ele projeta sobre o representante da Comédia Antiga e o da Comédia Nova. Sua perspectiva agonística, que separa os dois comediógrafos em polos diferentes, é construída a partir de um discurso retórico que procura convencer seu leitor da superioridade de Menandro. Esse poder de convencimento nos remete ao do personagem Pisetero, da comédia aristofânica Aves, que, também por meio de sua palavra, procura convencer o coro da comédia da qual ele faz parte.

É clara a influência que Plutarco recebeu do pensamento de sua época, que privilegiou o trabalho de Menandro e considerou a obra de Aristófanes menos valorosa. Contudo, reconhecemos que é incontestável para o Teatro Grego a importância de Aristófanes, que, como um verdadeiro intelectual de seu tempo, procurou alertar seu público sobre os problemas que a sociedade ateniense vivenciava, assumindo o papel de educador do povo. 


\section{REFERÊNCIAS BIBLIOGRÁFICAS}

Aristófanes (2000), As Aves. Tradução, introdução, notas e glossário de Adriane da Silva Duarte. São Paulo.

Bauzá, Hugo Francisco (2002), "Humanismo e acciones en las Vidas de Plutarco", in Ferreira, José Ribeiro (org.), Actas do Congresso Plutarco Educador da Europa. Porto, 181-193.

Duarte, Adriane da Silva (2000), O dono da voz e a voz do dono: a parábase na comédia de Aristófanes. São Paulo.

Féral, Cláudia Manoel Rached (2009), O agón na poética aristofânica: diversidade de forma e do conteúdo (tese). Araraquara.

Jaeger, Werner (2013), Paideia: a formação do homem grego. Tradução de Artur M. Parreira. São Paulo.

Silva, Luciene Lages (2013), "Lições de Plutarco sobre a Comédia Grega", in Pompeu, A. M. C.; Brose, Robert de; Araújo, O. L.; Oliveira, R. A. (org.), Identidade e Alteridade no Mundo Antigo. Fortaleza, 109-116. 